\title{
Karadeniz'de 2013-2014 Av Sezonunda Avlanan Hamsinin (Engraulis encrasicolus) Büyümesinin ve Ölüm Oranlarının Farklı Modellerle Belirlenmesi
}

\author{
Ebru SOLAK ${ }^{1}$, Sabri BİLGíN ${ }^{2 *}$ \\ ${ }^{\mathbf{1}}$ Recep Tayyip Erdoğan Üniversitesi, Su Ürünleri Fakültesi, Su Ürünleri Avlama ve İşleme Teknolojisi Bölümü, \\ Rize, Türkiye \\ ${ }^{2}$ Sinop Üniversitesi, Su Ürünleri Fakültesi, Su Ürünleri Avlama ve İşleme Teknolojisi Bölümü, Sinop, Türkiye \\ *Sorumlu Yazar: sbrbilgin@hotmail.com
}

Araștırma Makalesi

Geliş 24 Şubat 2020; Kabul 07 Ağustos 2020; Basım 01 Eylül 2020.

\begin{abstract}
Alıntılama: Solak, E., \& Bilgin, S. (2020). Karadeniz'de 2013-2014 av sezonunda avlanan hamsinin (Engraulis encrasicolus) büyümesinin ve ölüm oranlarının farklı modellerle belirlenmesi. Acta Aquatica Turcica, 16(3), 370-386. https://doi.org/10.22392/actaquatr.693367
\end{abstract}

\section{Özet}

Bu çalışma, Eylül 2013 ve Nisan 2014 tarihleri arasında Doğu Karadeniz sahillerinde avcılık yapan ticari gırgır teknelerinden örneklenen hamsi balığının yaşa dayalı altı farklı büyüme modeline göre (von Bertalanffy, Gompertz, Lojistik ya da Richards, Üssel, Morgan Mercer Flodin ve Weibull) büyümesi ve dört ölüm oranı modelline göre (Pauly, 1980; Djabali vd., 1993; Alagaraja, 1984 ve Srinath, 1998) ölüm oranının belirlenmesi amacıyla yürütülmüştür. Toplamda 5486 balık örneklenmiş ve 1265 balığın yaş tayini yapılmıştır. Dişilerin ortalama boyu erkeklerden daha büyük hesaplanmıştır $(P<$ $0,05)$. Erkekler için Weibull $\left(A I C=2593,5 ; L_{\infty}=19,6 \mathrm{~cm}\right.$ ve $\left.K=0,031 \mathrm{yl}^{-1}{ }^{-1}\right)$ ve Morgan Mercer Flodin $\left(A I C=2593,8 ; L_{\infty}=\right.$ $17,0 \mathrm{~cm}$ ve $\left.K=0,108 \mathrm{yvl}^{-1}\right)$, dişi için ise von Bertalanffy $\left(A I C=5725,42 ; L_{\infty}=11,1 \mathrm{~cm}\right.$ ve $K=2,064{\mathrm{y} 11^{-1}}^{-1}$ ve Üssel $($ AIC $=$ 5725,$4 ; L_{\infty}=11,1 \mathrm{~cm}$ ve $K=2,065 \mathrm{yll}^{-1}$ ) büyüme modellerinin en uygun modeller olduğu belirlenmiştir. Av eğrisi yöntemine

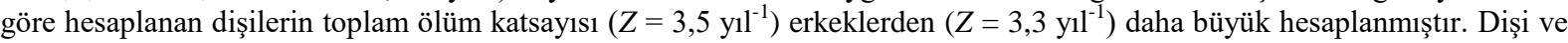
erkek bireyler için hesaplanan doğal ölüm oranı $(M)$ en düşük Djabali vd. (1993) modelinde, en yüksek ise Srinat (1998) modelinde hesaplanmıştır. Farklı büyüme modeli parametreleri kullanılarak hesaplanan doğal ölüm oranları ve $M$ verileri kullanılarak hesaplanan işletme oranı $(E)$ değerleri 2014-2015 av sezonunda hamsi stokunun optimum değerden $(E=0,5)$ daha yüksek bir derecede işletildiğini yani av baskısı altında olduğunu göstermiştir.

Anahtar kelimeler: Hamsi, büyüme modelleri, balıkçılık yönetimi, Karadeniz

Determination of Growth and Mortality Rates of Anchovy (Engraulis encrasicolus) Caught in the Black Sea in 20132014 Fishing Season with Different Models

\begin{abstract}
This study was conducted to describe age-based growth by six different growth models (von Bertalanffy, Gompertz, Logistic or Richards, Exponential, Morgan Mercer Flodin, Weibull) and mortality by four different empirical mortality models (Pauly, 1980; Djabali et al., 1993; Alagaraja, 1984; Srinath, 1998) of the anchovy obtained from commercial purse seine between September 2013 and April 2014 on the coast of the Eastern Black Sea. Of the 5486 sampled fish, the age of 1265 (824 females, 441 males) was determined. The mean total length $(T L)$ of females was significantly greater than the mean total length of males $(P<0.05)$. The Weibull $\left(A I C=2593.5 ; L_{\infty}=19.6 \mathrm{~cm}\right.$ and $K=0,031$ year $\left.^{-1}\right)$ and Morgan Mercer Flodin $\left(A I C=2593.8 ; L_{\infty}=17.0 \mathrm{~cm}\right.$ and $K=0.108$ year $\left.^{-1}\right)$ models for males, the von Bertalanffy $\left(A I C=5725.4 ; L_{\infty}=11.1\right.$ $\mathrm{cm}$ and $K=2.064$ year $\left.^{-1}\right)$ and Exponential $\left(A I C=5725.4 ; L_{\infty}=11.1 \mathrm{~cm}\right.$ and $K=2.065$ year $\left.^{-1}\right)$ models for females considered as the most suitable growth models. The total instantaneous mortality rate calculated by the catch curve method, $Z$, was estimated higher for females $\left(3.5 \mathrm{year}^{-1}\right)$ than males $\left(3.3\right.$ year $\left.^{-1}\right)$. Instantaneous natural mortality ratio, $M$, was estimated lower in Djabali et al. (1993) model and highest in Srinat (1998) model for both sexes. Natural mortality rates calculated using different growth model parameters and exploitation rate $(E)$ values calculated using $M$ data showed that the anchovy stock was exploitation at a higher degree than the optimum exploitation $(E=0.5)$ criterion, which is indicative of overfishing in the anchovy population in the 2014-2015 fishing season.
\end{abstract}

Keywords: Anchovy, growth models, fisheries management, Black Sea.

\section{GİRIŞ}

Hamsi (Engraulis encrasicolus Linnaeus, 1758) ülkemizde en çok avlanan küçük boylu pelajik bir balık olup, 3-4 yaşına kadar yaşayan kısa ömürlü ve çevresel duyarlılığı yüksek bir türdür (Prodanov 
vd., 1997; Bilgin, 2006; Bat vd., 2007; Ağırbaş vd., 2010). Bundan 60-70 y1l önce 1950'li yılların ortasında cinsi olgunluk boyuna ulaşmış bir hamsinin üreme sezonu boyunca 5 bin - 40 bin civarında yumurtayı 4 - 5 batında yumurtladığı rapor edilmesine rağmen (Slastenenko, 1955/1956), son yapılan bir çalışmada ise üreme sezonu boyunca (5 ay süreyle) ortalama 184 bin civarında yumurtayı günde 23 kez yumurtlayarak yaklaşık 50 batında yumurtladığı bildirilmiştir (Lisovenko ve Andrianov, 1996). Yumurtadan çıkan larva başlangıçta ağız açıklığına uygun büyüklükteki plankton ile beslenmekte ve hayat evresinin diğer aşamalarında (örneğin toplam boyu $>6,1 \mathrm{~cm}$ olan bireyler) başta balık yumurtası ve larvası olmak üzere Copepoda, Ctenophor gibi zooplanton ile ve Cyanophyceae, Chlorophyceae, Dinophyceae ve Bacillariophyceae gibi fitoplankton ile beslenir (Mazlum vd., 2017). Bu şekilde beslenerek cinsi olgunluğa kadar (1 yaş) hızlı bir şekilde büyüyen hamsi bir yaşında iken ömrü boyunca ulaşabileceği maksimum boyun \%70,6'lk kısmına ulaşır (Bilgin vd., 2016). Diğer balık türlerinde olduğu gibi Karadeniz'de avlanan hamsi stokları, bu şekilde büyüme ve üreme ile artmakta, balıkçılık kaynaklı ölümler ve doğal ölümlerle ise azalmaktadır (Erkoyuncu, 1995; Avşar, 2005).

Balıklarda büyüme zamanla boy ve ağırlık artışı olarak tanımlanmakla beraber, boyca büyüme hayat evrelerinin ilk aşamalarında muhtemelen cinsi olgunluğa kadarki aşamada hızlı ve yaş ilerledikçe yavaş bir seyir gösterir (von Bertalanffy, 1951; Erkoyuncu, 1995; Avşar, 2005). En yaygın hayvan büyümesi, büyüme oranlarının zamanla sürekli olarak azalması ve nihayetinde organizmanın yetişkinlerde sabit bir duruma ulaşmasıdır (von Bertalanffy, 1951). Belirli bir tür için bireylerin büyüme düzenini açıklamak için çeşitli büyüme modelleri önerilmiştir. Genellikle von Bertalanffy, Gompertz, Richards, Morgan Mercer Flodin ve Weibull gibi doğrusal olmayan büyüme modelleri yaşam boyunca belirli bir türün büyümesini tanımlamak için kullanılmaktadır (Fitzhugh, 1976; Quinn ve Deriso, 1999; Henderson ve Seaby, 2006). Bu modellerin büyüme eğrisi genellikle sigmoid veya S şeklinde bir eğridir. Tüm büyüme modelleri arasında, von Bertalanffy modeli çoğu balık türünün büyümesini tanımlamada en uygun olanıdır (Fitzhugh, 1976; Quinn ve Deriso, 1999; Henderson ve Seaby, 2006; Haddon, 2011). Ancak, hazırlanan yaş boy verileri seti kullanılarak yapılan hesaplamalarda, bazı balık türlerinin büyümesini tanımlamada veya kullanılan büyüme modelinin parametrelerinin biyolojik olarak yorumlanmasındaki uygunluk, veri uyumunun iyi olması, vücut şekli gibi nedenlerden dolayı (Fitzhugh, 1976) Karadeniz'de Zargana balığı (Belone euxini) (Bilgin vd., 2014) ve İskorpit balığı (Scorpaena porcus) (Demirhan ve Can, 2009) diğer bölgelerde ise Pervane balı̆̆ (Masturus lanceolatus) (Liu vd., 2009) ve Vatoz balığı (Bathyraja minispinosa) (Ainsley vd., 2011) gibi bir çok balık türünün büyümesi farklı büyüme modelleriyle tanımlanmıştır.

Bilgi toplama, analiz, planlama, danışma, karar verme, kaynakları pay etme, formülleştirme ve uyarlama, diğer balıkçılık hedeflerinin başarılması ve kaynakların verimliliğinin devamının sağlanması için gerekli durumlarda yaptırım uygulanan balıkçılık aktivitelerini yöneten kural veya düzenlemeler gibi entegre bir süreç olan balıkç1lık yönetimi (Cochrane, 2002) için balık stoklarındaki olası değişiklikleri izleme çalışmalarının sonuçları oldukça önemlidir. Türkiye'de hamsi balıkçılık yönetimine veri sağlamak amacıyla; popülasyon dinamiği kapsamında 1985 y1lından günümüze kadar özellikle av sezonları içerisinde hamsinin büyüme ve ölüm oranlarını içeren bir çok çalışma bazı av sezonlarında kesiklikler olsa da periyodik olarak yapılmıştır. Söz konusu çalışmalarda av sezonlarına göre hamsi için yaş-boy kompozisyonu, von Bertalanffy büyüme denklemi parametreleri $\left(L_{\infty}, K\right.$ ve $\left.t_{0}\right)$, balıkçlık $(F)$ ve doğal ölüm oranı $(M)$, işletme oranı $(E)$ gibi parametrelerin değişimi izlenmiş ve izlenmektedir. Bu çalışmada, Eylül 2013 ve Nisan 2014 tarihleri arasında (2013-2014 av sezonunda) Doğu Karadeniz sahillerinde avcılık yapan ticari gırgır teknelerinden örneklenen hamsi balığının $(E$. encrasicolus) yaş kompozisyonu, boy kompozisyonu, yaşlardaki ortalama boy değerleri, farklı büyüme modellerine göre hesaplanan büyüme parametreleri ve ölüm oranı incelenmiştir.

\section{MATERYAL ve YÖNTEM Çalışma Alanı ve Örnekleme}

Hamsi balığı örneklemeleri aylık olarak Eylül 2013 ve Nisan 2014 tarihleri arasında Doğu Karadeniz sahillerinde (Rize ve Trabzon sahilleri) avcılık yapan ticari girgir teknelerinden elde edilmiştir. Avcılık sonrasında yakalanan avdan bir kasa (yaklaşık $18 \mathrm{~kg}$ ) hamsi balığı alınmış ve incelenmek üzere Recep Tayyip Erdoğan Üniversitesi Su Ürünleri Fakültesi Laboratuvarına getirilmişlerdir. Laboratuvarda balıkların uzunluklar $1 \mathrm{~mm}$ hassasiyetle ölçülmüş, ağırlıklar $0,001 \mathrm{~g}$ hassasiyetle tartılmış ve cinsiyetleri belirlenerek kaydedilmiştir. Yaş tayininde kullanılmak üzere sagittal otolitleri çıkarılarak üzerine balık numarası ve örnekleme tarihi yazılı eppendorf tüplere 
yerleştirilerek ileride yaş tayinlerinin yapılması için saklanmışlardır.

\section{Yaş tayini}

\section{Yaş halkalarını belirlemek için uygulanan işlemler}

Hamsi otolitlerinin opak (koyu: kış halkası) ve hyalin (şeffaf: yaz halkası) halkaların belirlenmesi için farklı boylardaki balıklara ait sagitta otolitleri kullanılmıştır. En doğru şekilde yaş tayinlerinin yapılabilmesi için Avşar (2005) tarafından önerilen genel yaş tayini işlemi ölçüt alınarak sagitta otolitlere aşağıda belirtilen 5 farklı işlem uygulanmış, sagitta otolitlerin üzerindeki opak ve hyalin yaş halkalarının daha belirgin bir hale getirilmesi için uygun yaş belirleme prosedürü belirlenmiştir.

i) Farklı boylardaki balıklara $(\mathrm{n}=20)$ ait otolitler üzerinden ilk yaş okuma işlemi yapılmıştır. Ependolf tüplerinde bulunan otolitler, içerisinde \%96'l1k etil alkol çözeltisi konulan petri kaplarına ayr1 ayr1 yerleştirilmiş ve 5-10 dakika kadar bekletilmiştir. Otolitlerin üzerindeki zar baş ve işaret parmağı arasında ovularak çıkarılmış ve otolitler parlak bir görünüm almıştır. Bu şekilde hazırlanan otolitlerin yaş halkaları mikroskop altında incelenmiştir. Bu yöntem sonucunda incelenen otolitlerin yaş halkalarının belirgin olmadığı, otolitin çekirdeği ve en fazla bir yaş halkası görülebilmiştir.

ii) Farklı boylardaki balıklara $(\mathrm{n}=25)$ ait otolitler üzerinden ikinci yaş okuma işlemi yapılmıştır. Ependolf tüplerinde bulunan otolitlere 1. işlem uygulanmış ve otolitler temizlenmiştir. Daha sonra bu otolitler sırasıyla \%1'lik $\mathrm{HCl}$ çözeltisinde 3-5 dakika ve \%3-5'lik $\mathrm{NaOH}$ çözeltisinde 5-10 dakika kadar bekletilmiştir. Bu otolitler daha şeffaf bir görünüm alması ve zardan tamamen temizlenmesi için içerisinde $\% 40, \% 50, \% 60, \% 70$ ve $\% 80$ 'lık konsantrasyonlarda hazırlanmış etilalkol solüsyonu bulunan petri kaplarına sırasıyla 5-10 dakika kadar daha bekletilmişlerdir. Bu şekilde hazırlanan otolitler, içerisinde gliserin bulunan petri kabında mikroskop altında incelenmiştir. $\mathrm{Bu}$ yöntem neticesinde otolitin çekirdeği ve en fazla bir yaş halkası görülebilmiştir. Yapılan yaş okumalarında yaş halkalarının mikroskop altındaki görünümünden emin olunamamış ve yaş halkalarından doğru bir şekilde yaş okuması yapılamamıştır.

iii) Farklı boylardaki 15 balığa ait otolitler üzerinden üçüncü yaş okuma işlemi yapılmıştır. Bu otolitlere 1. ve 2. işlemler sırasıyla uygulanmış ancak ikinci işlemden farklı olarak otolitler etil alkol çözeltisine bekletilmeden otolitlerin daha şeffaf bir görünüm alması ve zardan tamamen temizlenmesi için tekrar içerisinde \%96'lık etil alkol çözeltisi bulunan petri kaplarında 5-10 dakika daha bekletilmiştir. Bu şekilde hazırlanan otolitler içerisinde gliserin bulunan petri kabında mikroskop altında incelenmiştir. Bu yöntemde incelenen otolitlerin yaş halkaları 1. ve 2. girişime göre daha net bir şekilde görülebilmiş ancak yaş okumalarından özellikle kalın otolitler için emin olunamamıştır.

iv) Bu işlem kalın yapıda olan 40 otolitler için (genellikle $11 \mathrm{~cm}$ den daha uzun boydaki balık otolitleri) uygulanmıştır. Ependolf tüplerinde bulunan otolitler, içerisinde \%96'lık etil alkol çözeltisi konulan petri kaplarına ayrı ayrı yerleştirilmiş ve 5-10 dakika kadar bekletilerek temizlenmiştir. $\mathrm{Bu}$ otolitler daha sonra sırasıyla 1., 2. ve 3. girişime göre konsantrasyonu artırılan \%10'luk $\mathrm{HCl}$ çözeltisinde otolitin kalınlığına göre 30-90 saniye ve \%25'lik $\mathrm{NaOH}$ çözeltisinde 10-30 dakika bekletilmiş ve ardından otolitler \%96'lık etil alkol çözeltisinde 5-10 dakika daha bekletilmiştir. $\mathrm{Bu}$ şekilde hazırlanan otolitler içerisinde gliserin bulunan petri kabına gömülerek 1 gece bekletilmiş (1013 saat) ve mikroskop altında otolitler incelenmiştir. Bu yöntem otolitlerin daha kalın olması ve yaş halkalarının hiçbir şekilde belirgin olmamasından dolayı uygulanmıştır. $\mathrm{Bu}$ yöntemde incelenen otolitlerin yaş halkaları birinci, ikinci ve üçüncü girişime göre genel olarak daha şeffaf ve daha görülebilir olmuş, fakat otolitlerin birçoğunda yaş halkaları yinede net bir şekilde görülememiş ve yaş okumalarından emin olunamamışır.

v) İnce otolitler için 3. girişimdeki işlemler uygulandıktan sonra sıfır numara su zımparası (Waterproof Silicon Carbide Paper FEPA P\#1200) kullanılarak otolitler hafiften zımparalanmıştır. Zımparalama işleminde otolitlerin zarar görmemesi için; otolitler mikroskop altında incelenerek yaş halkalarının görülebilir olması ve zımparadan dolayı yaş halkalarının kaybolmamasına dikkat edilmiştir. Kalın otolitler için (genellikle $11 \mathrm{~cm}$ den daha uzun boydaki balık otolitleri) 4. girişimdeki işlemler uygulandıktan sonra sıfır numara su zımparası kullanılarak otolitler hafiften zımparalanmıştır. Kalın otolitleri zımparalama işleminde de otolitlerin zarar görmemesi için otolitler mikroskop altında incelenmiş, yaş halkalarının görülebilir olması ve zımparadan dolayı kaybolmamasına dikkat edilmiştir. Bu şekilde hazırlanan otolitler tekrar \%96'l1k etil alkol çözeltisinde temizlendikten sonra içerisinde gliserin bulunan petri kabına gömülerek yaş halkalarının sayılması mikroskop altında yapılmıştır. Bu yöntem, opak ve hyalin halkaların daha net bir şekilde görülmesini sağlamıştır. $\mathrm{Bu}$ çalışmada örneklenen 5485 bireyden 1265 bireyin sagitta otolitlerinin yaş tayinine hazır hale 
getirilmesi 5. girişime göre yapılmış, yaş halkalarının sayılması $0,8 \mathrm{x}$ ile $8,0 \mathrm{x}$ arasındaki büyütmede Nikon DSFI1 dijital fotoğraf makinesi bağli Nikon SMZ1000 marka stereomikroskopu altında yapılmış ve otolitlerin fotoğrafları çekilmiştir (Şekil 1).

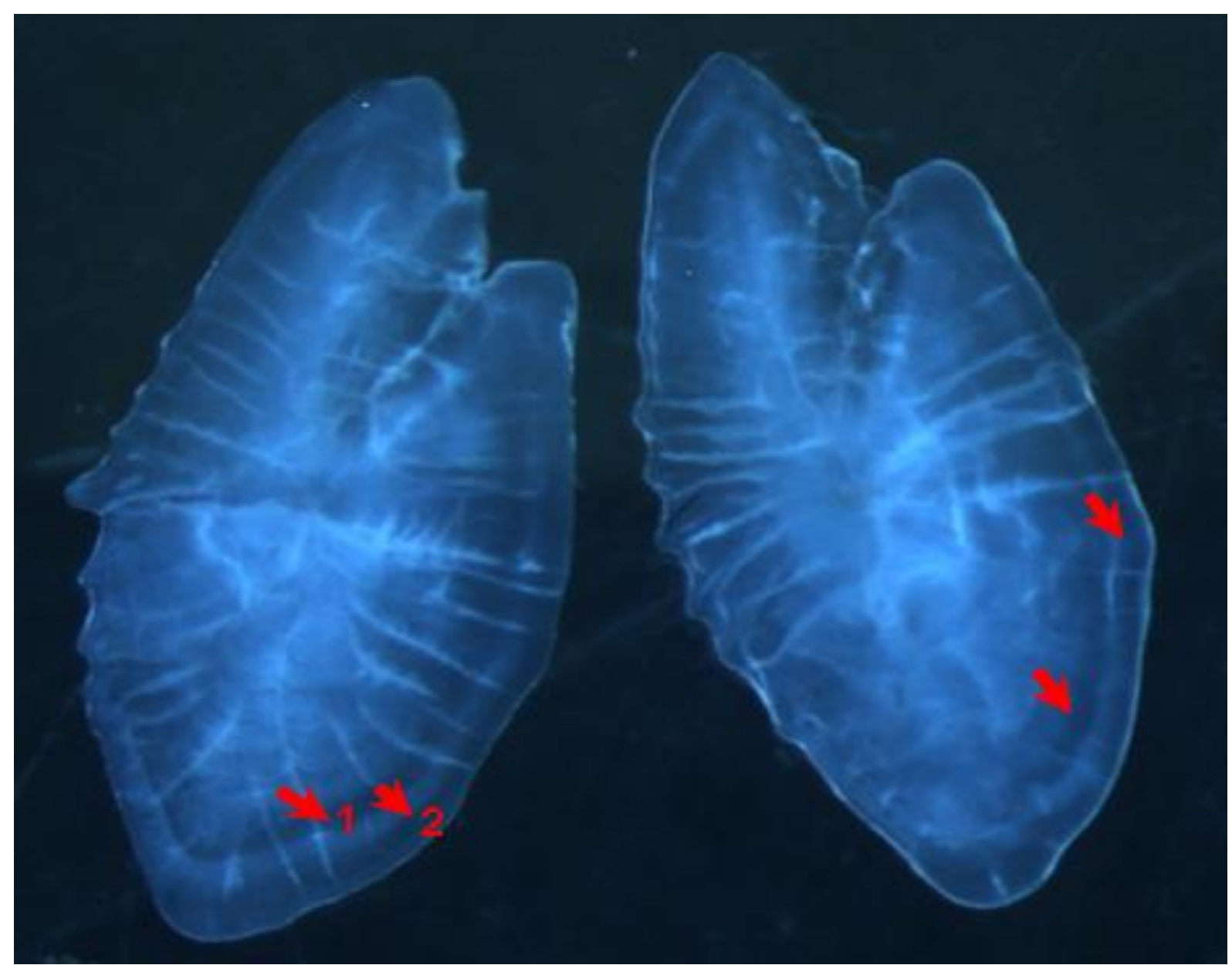

Şekil 1. Siyah zemin üzerine konmuş otolit zonlarının yukarıdan aydınlatmayla mikroskop altındaki görünüşü (orijinal).

\section{Büyüme}

\section{Boy - frekans dağılımı}

Dişi ve erkek bireylerin aylık boy - frekans dağılımı $0,5 \mathrm{~cm}$ aralıklı boy sınıflarına göre hesaplanmıştır. Boy dağılımları arasındaki fark Kolmogorov - Smirnov testi ile test edilmiştir. Dişi ve erkek bireylerin ortalama boyları arasındaki fark ise $\mathrm{t}$ - test ile analiz edilmiştir. İstatistiksel testler PAST versiyon 2.14 bilgisayar programı kullanılarak yapılmıştır (Hammer vd., 2001).

\section{Büyüme modelleri}

Hamsinin büyümesini güvenilir bir şekilde hesaplamak için 6 büyüme modeli (Gompertz, Lojistik ya da Richards eğrisi, Exponential (Üssel), Morgan Mercer Flodin (MMF), von Bertalanffy, Weibull) parametreleri dişi ve erkek bireylerin yaş - boy veri seti kullanılarak hesaplanmıştır. Hesaplamalarda kullanılan 6 büyüme modeli Tablo 1'de sunulmuştur. 
Tablo 1. Hamsinin yaş-boy veri setine Growth II programında uygulanan büyüme modelleri

\begin{tabular}{|c|c|c|c|}
\hline Büyüme model denklemi & Model parametreleri & Model adı & Taynak \\
\hline 1) $L_{t}=L_{\infty} e^{e^{-k(t-I)}}$ & $L_{\infty}(\mathrm{cm}), K\left(\mathrm{y}^{-1}{ }^{-1}\right), I(\mathrm{y} 1 \mathrm{l})$ & Gompertz & (Gompertz, 1825) \\
\hline 2) $L_{t}=\frac{L_{\infty}}{1+e^{-k(t-I)}}$ & $L_{\infty}, K, I$ & $\begin{array}{l}\text { Lojistik ya } \quad \text { da } \\
\text { Richards eğrisi }\end{array}$ & (Richards, 1959) \\
\hline 3) $L_{t}=L_{\infty}-\left(L_{\infty}-\beta\right) e^{(-(k t))}$ & $L_{\infty}, K, \beta(\mathrm{cm})$ & Exponential (Üssel) & (Everhart vd., 1975) \\
\hline 4) $L_{t}=L_{\infty}\left(1-e^{-K\left(t-t_{0}\right)}\right)$ & $L_{\infty}, K, t_{0}(\mathrm{y} 1 \mathrm{l})$ & von Bertalanffy & (von Bertalanffy, 1938) \\
\hline 5) $L_{t}=L_{\infty}-\frac{L_{\infty}-\beta}{1+(k t)^{\delta}}$ & $L_{\infty}, K, \beta$ & $\begin{array}{l}\text { Morgan Mercer } \\
\text { Flodin (MMF) }\end{array}$ & (Morgan vd., 1975) \\
\hline$t=\left[\frac{\delta-1}{\delta+1}\right]^{1 / \delta}$ & Morgan Mercer Flodin d & kkleminin bükülme no & tas 1 \\
\hline $\begin{array}{l}\text { 6) } L_{t}=L_{\infty}-\left(L_{\infty}-\beta\right) e^{\left(-(k t)^{\delta}\right)} \\
\left(\frac{1}{K}\right)\left(\frac{\delta-1}{\delta}\right)^{1 / \delta}\end{array}$ & $\begin{array}{l}L_{\infty}, K, \beta, \delta(\mathrm{y} 1) \\
\text { Weibull denkleminin bül }\end{array}$ & $\begin{array}{l}\text { Weibull } \\
\text { lime noktası }\end{array}$ & (Weibull, 1951) \\
\hline
\end{tabular}

Tablo 1'de belirtilen büyüme modellerinin parametreleri, yaş boy verileri kullanılarak her bir model için Growth II versiyon 2.1.0.48 bilgisayar programı (Henderson ve Seaby, 2006) kullanılarak hesaplanmiştir. Akaike Bilgi Kriteri (Akaike, 1974) en uygun modelin seçilmesinde ölçüt olarak alınmıştır. Akaike Bilgi Kriteri (AIC) indeksi hangi modelde daha düşük hesaplandıysa o model için veriler diğer modellere göre daha iyi fit yapmakta ve en uygun büyüme modeli olarak atanmaktadır (Akaike, 1974; Henderson ve Seaby, 2006; Burnham ve Anderson, 2002). Akaike Bilgi Kriteri aşağıdaki formüle göre hesaplanmıştır.

$$
A I C=N \log (W S S)+2 M,
$$

burada, $N=$ veri noktası sayısı, WSS = karelerinin farkının ağırlıklı toplamı, $M=$ model parametrelerinin sayısı olup, WSS aşağıdaki formüle göre hesaplanmıştır.

$$
W S S=\sum_{i=1}^{i=n} \frac{1}{S D_{i}^{2}}\left(Y_{o b s, i}-Y_{\text {calculated }, i}\right)^{2}
$$

burada $S D=$ yaşlardaki ortalama boyların standart sapmasıdır.

\section{Büyüme performansı}

Büyüme performansı indeksi ( $\Phi$ ') Pauly ve Munro (1984) tarafından önerilen aşağıdaki formüle göre hesaplanmıştır.

$$
\Phi^{\prime}=\log (K)+2 \log \left(L_{\infty}\right) .
$$

\section{Ölüm oranı}

\section{Toplam ölüm oranı}

Toplam ölüm oranı $(Z)$ av eğrisi yöntemine göre (Pauly, 1984) aşağıdaki formül kullanılarak hesaplanmıştır.

$$
\ln \left(N_{i}\right)=a+b t_{i}
$$


burada, $t_{\mathrm{i}}=$ i'nci yaş sınıfi, $N_{i}=$ i'nci yaş sınıfındaki balık sayısıdır. $a$ ve $b$ ise yaşlardaki balık sayısının doğal logaritmasına karşılık hesaplanan regresyon denkleminin kesim noktasını $(a)$, eğimini $(b)$ ifade etmektedir. Buradan $Z=-\mathrm{b}$ şeklinde hesaplanır.

\section{Doğal ölüm oranı}

Doğal ölüm oranı (M); Pauly (1980), Djabali vd. (1993), Alagaraja (1984) ve Srinath (1998) tarafından önerilen aşağıdaki dört farklı formül kullanılarak hesaplanmıştır.

$$
\begin{aligned}
& \log M=0,8\left(-0,0066-0,279 \log T L_{\infty}+0,6543 \log K+0,4634 \log T\right)(\text { Pauly, 1980) } \\
& \log M=0,8\left(-0,736-0,114 \log T L_{\infty}+0,522 \log K+0,583 \log T\right)(\text { Djabali vd., 1993) } \\
& M=1,680 K \text { (Srinath, 1998) } \\
& M=1,535 K \text { (Alagaraja, 1984) }
\end{aligned}
$$

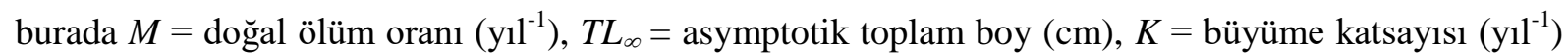
parametreleridir. $T$ ise ortalama yüzey su sıcaklığ $\left({ }^{\circ} \mathrm{C}\right.$ ) olup bu çalışmada $15^{\circ} \mathrm{C}$ olarak alınmıştır (Bat vd., 2007; Ağırbaş vd., 2010).

\section{Balıkçılık ölüm oranı}

Balıkçılık ölüm oranı $(F)$ av eğrisi yöntemine göre hesaplanan toplam ölüm oranından yukarıda belirtilen dört doğal ölüm oranına [Pauly (1980), Djabali vd. (1993), Alagaraja (1984) ve Srinath (1998)] göre hesaplanan doğal ölüm oranlarından çıkarılarak aşağıdaki formül kullanılarak hesaplanmıştır.

$$
F=Z-M
$$

burada $F=$ balıkçılık ölüm oranı $\left(\mathrm{y} 11^{-1}\right), Z=$ toplam ölüm oranı $\left(\mathrm{y}^{1} 1^{-1}\right), M=\operatorname{doğal~ölüm~oranıdır~}\left(\mathrm{y} 11^{-1}\right)$.

\section{İşletme oranı}

İşletme oranı $\left(E, \mathrm{y}_{1} 1^{-1}\right)$, Ricker (1975) tarafindan önerilen $E=F / Z$ denklemine göre hesaplanmıştır. Balıkçılık ölüm oranı, doğal ölüm oranı ve işletme oranı dişi ve erkek bireyler için altı büyüme modelinin parametreleri kullanılarak her bir model sonuçlarına göre ayrı ayrı hesaplanmıştır.

\section{BULGULAR}

\section{Boy kompozisyonu}

Araştırmada 8 aylık süre içerisinde 5485 adet (3336 dişi, 2149 erkek) hamsi örneklenmiştir. Dişiler 5,9 ve $13,8 \mathrm{~cm}$ arasinda (ortalama10,8 $\pm 0,02 \mathrm{~cm}$ ), erkekler 6,0 ve $13,2 \mathrm{~cm}$ arasinda (ortalama $10,1 \pm 0,03 \mathrm{~cm}$ ) dağılım göstermiştir. Tüm bireyler (dişi+erkek) ise 5,9 ve 13,8 cm arasında (ortalama $10,5 \pm 0,02 \mathrm{~cm}$ ) dağılım göstermiştir. Dişilerin ortalama boyu erkeklerden istatistiksel olarak daha büyük olarak hesaplanmıştır ( $t$ test: $\mathrm{P}<0,05)$. Ayrıca dişi ve erkek bireylerin boy frekans dağılımları arasındaki fark istatistiksel olarak önemli hesaplanmıştır (Kolmogorov-Simirnov test: $\mathrm{d}=0,277045, P$ $<0,05)$. Boy frekans dağılımına göre örneklenen bireylerin $\% 60,8$ 'i dişi ve $\% 39,2$ 'si ise erkek bireylerden oluşmuştur. $9 \mathrm{~cm}$ boy sınırının altında dişilerin oranı \%3,3, erkeklerin oranı ise $\% 6,7$ olarak hesaplanmıştır. Hamsinin minimum avlanabilir boyu (MLS) olan $9 \mathrm{~cm}$ boyundaki bireylerin Eylül 2013 ile Aralık 2013 tarihleri arasında örneklendiği görülmektedir (Tablo 2, 3). 
Tablo 2. Cinsiyetlere göre hamsi balığının aylık boy frekans dağılımı

\begin{tabular}{|c|c|c|c|c|c|c|c|c|c|c|c|c|c|c|c|c|c|}
\hline \multirow{3}{*}{ Boy sınıfi (cm) } & \multicolumn{8}{|l|}{ Dişi } & \multicolumn{8}{|l|}{ Erkek } & \multirow{3}{*}{ Toplam } \\
\hline & \multicolumn{4}{|l|}{2013} & \multicolumn{4}{|l|}{2014} & \multicolumn{4}{|l|}{2013} & \multicolumn{4}{|l|}{2014} & \\
\hline & Eylül & Ekim & Kasım & Aralık & Ocak & Şubat & Mart & Nisan & Eylül & Ekim & Kasım & Aralık & Ocak & Şubat & Mart & Nisan & \\
\hline$<6$ & 1 & & & & & & & & & & & 1 & & & & & 2 \\
\hline $6-6,5$ & & & & & & & & & 1 & & & 5 & & & & & 6 \\
\hline $6,5-7,0$ & & & & 2 & & & & & 2 & 1 & & 34 & & & & & 39 \\
\hline $7,0-7,5$ & 1 & 1 & 1 & 19 & & & & & 3 & 1 & 8 & 28 & & & & 1 & 63 \\
\hline $7,5-8,0$ & 1 & 2 & 5 & 20 & & & & & 2 & 4 & 15 & 52 & & & & & 101 \\
\hline $8,0-8,5$ & 3 & 9 & 9 & 27 & & & 2 & & 14 & 7 & 13 & 54 & & & & & 138 \\
\hline $8,5-9,0$ & 27 & 12 & 12 & 25 & 1 & 1 & & & 38 & 8 & 17 & 57 & 1 & & & & 199 \\
\hline $9,0-9,5$ & 61 & 43 & 24 & 44 & 3 & & 8 & & 80 & 35 & 33 & 78 & 2 & 6 & 6 & 2 & 425 \\
\hline $9,5-10,0$ & 119 & 72 & 57 & 72 & 24 & 8 & 30 & 7 & 105 & 64 & 57 & 82 & 21 & 8 & 10 & 5 & 741 \\
\hline $10,0-10,5$ & 84 & 88 & 105 & 67 & 46 & 42 & 46 & 35 & 97 & 78 & 76 & 46 & 37 & 43 & 28 & 20 & 938 \\
\hline $10,5-11,0$ & 74 & 78 & 79 & 110 & 75 & 60 & 95 & 128 & 42 & 79 & 46 & 35 & 49 & 44 & 38 & 42 & 1074 \\
\hline $11,0-11,5$ & 29 & 41 & 52 & 131 & 76 & 67 & 108 & 172 & 10 & 33 & 22 & 41 & 32 & 34 & 24 & 40 & 912 \\
\hline $11,5-12,0$ & 3 & 17 & 34 & 103 & 59 & 72 & 50 & 79 & 1 & 9 & 13 & 27 & 19 & 21 & 13 & 13 & 533 \\
\hline $12,0-12,5$ & 1 & 8 & 15 & 33 & 31 & 61 & 28 & 24 & & 5 & 2 & 4 & 7 & 6 & 3 & 2 & 230 \\
\hline $12,5-13,0$ & & 3 & 3 & 6 & 12 & 19 & 9 & 6 & & & & & 2 & 3 & & & 63 \\
\hline $13,0-13,5$ & & 3 & 2 & 1 & 1 & 4 & 2 & 4 & & & & & 1 & 1 & & & 19 \\
\hline $13,5-14,0$ & & & & & 1 & & & 1 & & & & & & & & & 2 \\
\hline Toplam & 404 & 377 & 398 & 660 & 329 & 334 & 378 & 456 & 395 & 324 & 302 & 544 & 171 & 166 & 122 & 125 & 5485 \\
\hline
\end{tabular}


Tablo 3. Yaş tayini yapılan bireylerin cinsiyetlere göre aylık boy frekans dağılımı

\begin{tabular}{|c|c|c|c|c|c|c|c|c|c|c|c|c|c|c|c|c|c|}
\hline \multirow{3}{*}{ Boy sınıfi (cm) } & \multicolumn{8}{|l|}{ Dişi } & \multicolumn{8}{|c|}{ Erkek } & \multirow{3}{*}{ Toplam } \\
\hline & \multicolumn{4}{|l|}{2013} & \multicolumn{4}{|l|}{2014} & \multicolumn{4}{|c|}{2013} & \multicolumn{4}{|l|}{2014} & \\
\hline & Eylül & Ekim & Kasım & Aralık & Ocak & Şubat & Mart & Nisan & Eylül & Ekim & Kasım & Aralık & Ocak & Şubat & Mart & Nisan & \\
\hline \multicolumn{18}{|c|}{. } \\
\hline $6-6,5$ & & & & & & & & & & & & 3 & & & & & 3 \\
\hline $6,5-7,0$ & & & & 1 & & & & & 1 & 1 & & 22 & & & & & 25 \\
\hline $7,0-7,5$ & 1 & 1 & & 9 & & & & & 3 & 1 & 4 & 14 & & & & 1 & 34 \\
\hline $7,5-8,0$ & 1 & 1 & 5 & 9 & & & & & 1 & 2 & 12 & 19 & & & & & 50 \\
\hline $8,0-8,5$ & 2 & 6 & 6 & 9 & & & 2 & & 9 & 6 & 9 & 10 & & & & & 59 \\
\hline $8,5-9,0$ & 14 & 7 & 8 & 8 & 1 & 1 & & & 15 & 3 & 7 & 11 & 1 & & & & 76 \\
\hline $9,0-9,5$ & 23 & 12 & 5 & 12 & 1 & & 6 & & 23 & 10 & 4 & 13 & 1 & 4 & 4 & 1 & 119 \\
\hline $9,5-10,0$ & 21 & 8 & 5 & 10 & 14 & 5 & 16 & 5 & 9 & 10 & 9 & 12 & 10 & 5 & 6 & 2 & 147 \\
\hline $10,0-10,5$ & 4 & 6 & 6 & 9 & 20 & 24 & 18 & 10 & 9 & 3 & 11 & 7 & 8 & 19 & 9 & 2 & 165 \\
\hline $10,5-11,0$ & 9 & 2 & 2 & 14 & 16 & 17 & 31 & 18 & 2 & 4 & 3 & 3 & 4 & 9 & 4 & 4 & 142 \\
\hline $11,0-11,5$ & 4 & 9 & 4 & 16 & 15 & 9 & 18 & 28 & 1 & 3 & 7 & 4 & 4 & 2 & & 4 & 128 \\
\hline $11,5-12,0$ & & 11 & 13 & 36 & 19 & 10 & 15 & 21 & & 1 & 8 & 8 & 2 & 1 & 3 & 2 & 150 \\
\hline $12,0-12,5$ & & 4 & 11 & 19 & 19 & 24 & 11 & 16 & & 4 & 2 & 1 & 3 & & & & 114 \\
\hline $12,5-13,0$ & & 1 & 2 & 5 & 7 & 11 & 6 & 4 & & & & & 1 & & & & 37 \\
\hline $13,0-13,5$ & & 2 & 2 & 1 & & 4 & 1 & 3 & & & & & 1 & & & & 14 \\
\hline $13,5-14,0$ & & & & & 1 & & & 1 & & & & & & & & & 2 \\
\hline Toplam & 79 & 70 & 69 & 158 & 113 & 105 & 124 & 106 & 73 & 48 & 76 & 127 & 35 & 40 & 26 & 16 & 1265 \\
\hline
\end{tabular}




\section{Yaş kompozisyonu}

Yaş tayını yapılan 1265 bireyin (824 dişi, 441 erkek) yaşlardaki ortalama boyları, yaşlardaki sayıları ve yüzdeleri Tablo 4'de, yaş - boy anahtarı ise Tablo 5'de sunulmuştur. Dişilerin yaş kompozisyonu: \%4,1'i 0 yaş, \%18'i I yaş, \%42'si II yaş ve \%1'i III yaş şeklinde, erkeklerin yaş kompozisyonu ise \%9'u 0 yaş, \%11'i I yaş, \%15'i II yaş ve \%1'i III yaş şeklinde hesaplanmıştır. Hem dişiler $(\% 42)$ hem de erkekler (\%15) II yaşında daha fazla oranda tespit edilmişstir. Yaş tayini yapılan bireylerin baskın oldukları yaş iki cinsiyet içinde II yaş grubudur. Sifir yaş sınıfındaki bireylerin boy aralı̆̆ dişiler için 6,9 ile $8,9 \mathrm{~cm}$ arasında (ortalama $=8,0 \pm 0,07$ ), erkekler için ise 6,3 ile $9,4 \mathrm{~cm}$ arasında (ortalama $=7,6 \pm 0,07$ ) tespit edilmiştir.

Tablo 4. Yaş tayini yapılan bireylerin yaşlardaki ortalama boy $(T L) \pm$ standart hata (en küçük - en büyük) değerleri ve yaş kompozisyonu. $\mathrm{n}=$ örnek sayı, $(\%)=$ yaşlardaki yüzde oranı ifade etmektedir.

\begin{tabular}{cllllll}
\hline \hline \multirow{2}{*}{ Yaş (yıl) } & \multicolumn{2}{c}{ Dişi } & \multicolumn{2}{c}{ Erkek } & \multicolumn{2}{c}{ Tüm (dişi+erkek) } \\
\cline { 2 - 7 } & $\mathbf{T L}(\mathbf{c m})$ & $\mathbf{n}(\boldsymbol{\%})$ & $\boldsymbol{T L} \mathbf{( c m )}$ & $\mathbf{n}(\%)$ & $\boldsymbol{T L} \mathbf{( c m})$ & $\mathbf{n}(\%)$ \\
\hline \multirow{2}{*}{0} & $8,0 \pm 0,07$ & $50(\% 4)$ & $7,6 \pm 0,07$ & $111(\% 9)$ & $7,7 \pm 0,05$ & $161(\% 13)$ \\
& $(6,9-8,9)$ & & $(6,3-9,4)$ & & $(6,3-9,4)$ & \\
I & $10,8 \pm 0,08$ & $222(\% 18)$ & $9,7 \pm 0,08$ & $133(\% 11)$ & $10,4 \pm 0,07$ & $355(\% 28)$ \\
& $(7,9-13,2)$ & & $(7,9-12,1)$ & & $(7,9-13,2)$ & \\
II & $11,0 \pm 0,05$ & $535(\% 42)$ & $10,3 \pm 0,07$ & $190(\% 15)$ & $10,8 \pm 0,04$ & $725(\% 57)$ \\
& $(8,7-13,5)$ & & $(8,4-12,6)$ & & $(8,4-13,5)$ & \\
III & $12,7 \pm 0,15$ & $17(\% 1)$ & $12,3 \pm 0,22$ & $7(\% 1)$ & $12,6 \pm 0,13$ & $24(\% 2)$ \\
& $(11,9-13,8)$ & & $(11,2-13,1)$ & & $(11,2-13,8)$ & \\
\multirow{2}{*}{ Tüm (dişi+erkek) } & $10,8 \pm 0,05$ & $824(\% 65)$ & $9,5 \pm 0,07$ & $441(\% 35)$ & $10,3 \pm 0,04$ & $1265(\% 100)$ \\
& $(6,9-13,8)$ & & $(6,3-13,1)$ & & $(6,3-13,8)$ & \\
\hline \hline
\end{tabular}

Tablo 5. 2014-2015 av sezonunda avlanan hamsinin cinsiyetlere göre yaş - boy anahtarı

\begin{tabular}{|c|c|c|c|c|c|c|c|c|c|}
\hline \multirow{3}{*}{ Boy sınıfı (cm) } & \multirow{2}{*}{\multicolumn{4}{|c|}{$\frac{\text { Dişi }}{\text { Yaş (yıl) }}$}} & \multicolumn{4}{|c|}{ Erkek } & \multirow{3}{*}{ Tüm (dişi+erkek) } \\
\hline & & & & & \multicolumn{4}{|c|}{ Yaş (yıl) } & \\
\hline & $\mathbf{0}$ & $\mathbf{I}$ & II & III & 0 & I & II & III & \\
\hline$<6$ & & & & & & & & & 0 \\
\hline $6-6,5$ & & & & & 3 & & & & 3 \\
\hline $6,5-7,0$ & 1 & & & & 24 & & & & 25 \\
\hline $7,0-7,5$ & 11 & & & & 23 & & & & 34 \\
\hline $7,5-8,0$ & 14 & 2 & & & 31 & 3 & & & 50 \\
\hline $8,0-8,5$ & 16 & 9 & & & 17 & 14 & 3 & & 59 \\
\hline $8,5-9,0$ & 8 & 9 & 22 & & 11 & 18 & 8 & & 76 \\
\hline $9,0-9,5$ & & 21 & 38 & & 2 & 23 & 35 & & 119 \\
\hline $9,5-10,0$ & & 28 & 56 & & & 25 & 38 & & 147 \\
\hline $10,0-10,5$ & & 31 & 66 & & & 26 & 42 & & 165 \\
\hline $10,5-11,0$ & & 22 & 87 & & & 9 & 24 & & 142 \\
\hline $11,0-11,5$ & & 30 & 73 & & & 8 & 16 & 1 & 128 \\
\hline $11,5-12,0$ & & 32 & 89 & 4 & & 6 & 18 & 1 & 150 \\
\hline $12,0-12,5$ & & 28 & 72 & 4 & & 1 & 5 & 4 & 114 \\
\hline $12,5-13,0$ & & 7 & 25 & 4 & & & 1 & & 37 \\
\hline $13,0-13,5$ & & 3 & 7 & 3 & & & & 1 & 14 \\
\hline $13,5-14,0$ & & & & 2 & & & & & 2 \\
\hline Tüm (dişi+erkek) & 50 & 222 & 535 & 17 & 111 & 133 & 190 & 7 & 1265 \\
\hline
\end{tabular}

\section{Büyüme modelleri}

Hamsinin büyümesi; Gompertz, Lojistik, Exponential (üssel), Morcan Mercer Flodin, von Bertalanffy ve Weibull büyüme modellerine göre hesaplanmıştır. Erkekler için 6 büyüme modeli parametrelerinin hepsi hesaplanmış ancak dişiler için ise Morcan Mercer Flodin ve Weibull büyüme modellerinin parametreleri oluşturulan yaş - boy veri setinin Growth II programında uygun fit 
yapmaması nedeniyle hesaplanamamıştır. Hem dişi hem de erkek bireyleri için 6 büyüme modeline göre hesaplanan büyüme parametreleri, $A I C$ ve büyüme performansı sonuçları Tablo 6'da gösterilmiştir.

Tablo 6. Hamsi için hesaplanan büyüme model parametreleri. $A I C=$ Akaike Bilgi Kriteri, $L_{\infty}=$ asymptotik boy $(\mathrm{cm}), K=$ büyüme katsayısı $\left(\mathrm{y}^{-1}{ }^{-1}\right), t_{o}=$ balık boyunun kuramsal olarak sıfıra eşit olduğundaki yaş ya da embriyonik yaş (yıl), $\beta=$ daha düşük asymptotik boy ( $t=0$ deki boy), $I=$ etki noktasındaki yaş (yıl), $\delta=$ etki noktasını kontrol eden parametre (yıl), $\Phi^{\prime}=$ büyüme performans indeksi.

\begin{tabular}{|c|c|c|c|c|c|c|c|c|}
\hline \multirow[b]{2}{*}{ Büyüme modeli } & \multicolumn{6}{|c|}{ Büyüme modeli parametreleri } & \multirow[b]{2}{*}{$A I C$} & \multirow{2}{*}{$\begin{array}{l}\text { Büyüme } \\
\text { performans } \\
\Phi \\
\end{array}$} \\
\hline & $\begin{array}{l}L_{\infty} \\
(\mathbf{c m})\end{array}$ & $\begin{array}{l}K \\
\left(\mathrm{yll}^{-1}\right)\end{array}$ & $\begin{array}{l}t_{0} \\
(\text { yil) }\end{array}$ & $\begin{array}{l}\beta \\
(\mathrm{cm})\end{array}$ & $\begin{array}{l}I \\
(\mathrm{yil})\end{array}$ & $\begin{array}{l}\delta \\
(\text { yil) }\end{array}$ & & \\
\hline \multicolumn{9}{|l|}{ Dişi } \\
\hline Gompertz & 11,1 & 2,182 & & & $-0,510$ & & 5727,99 & 2,427 \\
\hline Lojistik & 11,1 & 2,429 & & & $-0,384$ & & 5725,75 & 2,477 \\
\hline Exponential (Üssel) & 11,1 & 2,065 & & 7,97 & & & 5725,42 & 2,408 \\
\hline $\begin{array}{l}\text { Morgan Mercer Flodin } \\
\text { von Bertalanffy (VBGF) }\end{array}$ & 11,1 & 2,064 & $-0,611$ & & & & 5725,42 & 2,408 \\
\hline \multirow{2}{*}{\multicolumn{9}{|c|}{$\begin{array}{l}\text { Weibull } \\
\text { Erkek }\end{array}$}} \\
\hline & & & & & & & & \\
\hline Gompertz & 10,7 & 1,219 & & & $-0,891$ & & 2599,53 & 2,145 \\
\hline Lojistik & 10,7 & 1,360 & & & $-0,682$ & & 2599,31 & 2,192 \\
\hline Exponential & 10,8 & 1,027 & & 7,64 & & & 2597,80 & 2,078 \\
\hline Morgan Mercer Flodin & 17,0 & 0,108 & & 7,63 & & 0,572 & 2593,82 & 1,494 \\
\hline von Bertalanffy & 10,8 & 1,027 & $-1,197$ & & & & 2597,80 & 2,078 \\
\hline Weibull & 19,6 & 0,031 & & 7,63 & & 0,422 & 2593,05 & 1,076 \\
\hline
\end{tabular}

Akaike Bilgi Kriteri indeksi dişiler için von Bertalanffy $(A I C=5725,42)=$ Exponential $(A I C=$ $5725,42)<$ Lojistik $(A I C=5725,75)<$ Gompertz $(A I C=5727,99)$ şeklinde, erkekler için ise Weibull $(A I C=2593,05)<$ Morgan Mercer Flodin $(A I C=2593,82)<$ von Bertalanffy $(A I C=2597,80)=$ Exponential $(A I C=2597,80)<$ Lojistik $(A I C=2599,31)<$ Gompertz $(A I C=2599,53)$ şeklinde hesaplanmıştır (Tablo 6). Dişi ve erkek bireylerde Gompertz büyüme modelinde hesaplanan $A I C$ değerinin en yüksek değerde olduğu, daha sonra dişiler için diğer üç modelinde (von Bertalanffy, Exponential, Lojistik) neredeyse aynı AIC değerine sahip olduğu belirlenmiştir. Ayrıca erkeklerde Weibull ile Morgan Mercer Flodin ve von Bertalanffy ile Exponential modellerinde hesaplanan AIC değerleri ise birbirlerine yakın bulunmuştur.

Ölüm oranı

Anlık ölüm oranı (Z)

Av eğrisi regresyon denklemi dişiler için $\mathrm{y}=-3,4491 \mathrm{x}+13,18$ şeklinde $\left(Z=3,4491 \mathrm{y}^{1}{ }^{-1}\right)$, erkekler için $\mathrm{y}=-3,3011 \mathrm{x}+11,849\left(Z=3,3011 \mathrm{yll}^{-1}\right)$, tüm bireyler için (dişi+erkek) ise $\mathrm{y}=-3,4081 \mathrm{x}+13,402$ $\left(Z=3,4081 \mathrm{yll}^{-1}\right)$ şeklinde hesaplanmıştır.

\section{Doğal ölüm oranı $(M)$ ve işletme oranı $(E)$}

Cinsiyetlere göre farklı büyüme modellerinden elde edilen büyüme parametreleri (Tablo 6) kullanılarak, Pauly (1980), Djabali vd. (1993), Alagaraja (1984) ve Srinath (1998) modellerine göre hesaplanan $M$ değerleri ve bu $M$ verileri kullanılarak hesaplanan $E$ değerleri Tablo 7'de sunulmuştur. Dişi ve erkek bireyler için hesaplanan ortalama $M$ değeri en düşük Djabali vd. (1993) modelinde, en yüksek ise Srinat (1998) modelinde hesaplanmıştır. Erkeler için Pauly (1980) ve Alagaraja (1984) modeline göre hesaplanan ortalama $M$ değerleri birbirine benzer hesaplanmıştır. Ancak, dişiler için Alagaraja (1984) modeline göre hesaplanan ortalama $M$ değeri $\left(3,4 \pm 0,13 \mathrm{y}_{1}{ }^{-1}\right)$ Pauly (1980) modeline göre hesaplanan ortalama $M$ değerinden $\left(2,4 \pm 0,05 \mathrm{yil}^{-1}\right)$ yüksek bulunmuştur. Dişi bireyler için sadece Djabali vd. (1993) yöntemine göre belirlenen $M$ değerleri kullanılarak hesaplanan işletme oranı $(E=$ $\left.0,71 \pm 0,005{\mathrm{y} 11^{-1}}^{-}\right) 0,5$ değerinden büyük, diğer yöntemlere göre belirlenen $M$ değerleri ile hesaplanan $E$ değerleri ise 0,5 değerinden küçük bulunmuştur. Diğer taraftan erkek bireyler için 4 yönteme göre belirlenen $M$ değerleri kullanılarak hesaplanan $E$ değerleri ise $0,5^{\prime}$ den büyük hesaplanmıştır. 
Tablo 7. Farklı büyüme modeli parametreleri kullanılarak hesaplanan doğal ölüm oranları $\left(M\right.$, yıl $\left.{ }^{-1}\right)$ ve verileri kullanılarak hesaplanan işletme oranı $\left(E, \mathrm{y}^{1} \mathrm{l}^{-1}\right)$ değerleri. $\mathrm{SH}=\mathrm{Standart}$ hata.

\begin{tabular}{|c|c|c|c|c|c|}
\hline \multirow[b]{2}{*}{ Büyüme modeli } & \multicolumn{4}{|c|}{ Doğal ölüm oranı $(M)$ modeli } & \\
\hline & $\begin{array}{l}\text { Pauly } \\
(1980)\end{array}$ & $\begin{array}{l}\text { Srinat } \\
(1998)\end{array}$ & $\begin{array}{l}\text { Alagaraja } \\
\text { (1984) }\end{array}$ & $\begin{array}{l}\text { Djabali vd. } \\
\text { (1993) }\end{array}$ & \\
\hline Dişi ${ }_{+}$ & & & & & Ort. $M q$ \\
\hline Gompertz & 2,370 & 3,666 & 3,349 & 1,014 & 2,600 \\
\hline Lojistik & 2,507 & 4,081 & 3,729 & 1,060 & 2,844 \\
\hline Exponential (Üssel) & 2,303 & 3,469 & 3,170 & 0,991 & 2,483 \\
\hline VBGF & 2,302 & 3,468 & 3,168 & 0,990 & 2,482 \\
\hline Ort. $M \pm S H$ & $2,371 \pm 0,048$ & $3,671 \pm 0,144$ & $3,354 \pm 0,132$ & $1,014 \pm 0,016$ & $2,602 \pm 0,085$ \\
\hline Erkek $\sigma^{\pi}$ & & & & & Ort. $M$ Øे \\
\hline Gompertz & 1,762 & 2,048 & 1,871 & 0,798 & 1,620 \\
\hline Lojistik & 1,866 & 2,285 & 2,088 & 0,835 & 1,768 \\
\hline Exponential (Üssel) & 1,607 & 1,725 & 1,576 & 0,742 & 1,413 \\
\hline MMF & 0,447 & 0,181 & 0,166 & 0,278 & 0,268 \\
\hline VBGF & 1,607 & 1,725 & 1,576 & 0,742 & 1,413 \\
\hline Weibull & 0,225 & 0,052 & 0,048 & 0,163 & 0,122 \\
\hline Ort. $M \pm S H$ & $1,252 \pm 0,294$ & $1,336 \pm 0,396$ & $1,221 \pm 0,361$ & $0,593 \pm 0,120$ & $1,101 \pm 0,292$ \\
\hline Dişi $q$ & \multicolumn{4}{|c|}{ İşletme oranı $(E)$} & Ort. $E$ 우 \\
\hline Gompertz & 0,313 & $-0,063$ & 0,029 & 0,706 & 0,246 \\
\hline Lojistik & 0,273 & $-0,183$ & $-0,081$ & 0,693 & 0,175 \\
\hline Exponential (Üssel) & 0,332 & $-0,006$ & 0,081 & 0,713 & 0,280 \\
\hline VBGF & 0,333 & $-0,005$ & 0,081 & 0,713 & 0,280 \\
\hline Ort. $E \pm S H$ & $0,313 \pm 0,014$ & $-0,064 \pm 0,042$ & $0,028 \pm 0,038$ & $0,706 \pm 0,005$ & $0,246 \pm 0,025$ \\
\hline Erkek $\sigma^{\lambda}$ & \multicolumn{4}{|c|}{ İşletme oranı $(E)$} & Ort. $E$ ठ̀ \\
\hline Gompertz & 0,466 & 0,380 & 0,433 & 0,758 & 0,509 \\
\hline Lojistik & 0,435 & 0,308 & 0,368 & 0,747 & 0,464 \\
\hline Exponential (Üssel) & 0,513 & 0,477 & 0,522 & 0,775 & 0,572 \\
\hline MMF & 0,865 & 0,945 & 0,950 & 0,916 & 0,919 \\
\hline VBGF & 0,513 & 0,477 & 0,522 & 0,775 & 0,572 \\
\hline Weibull & 0,932 & 0,984 & 0,986 & 0,951 & 0,963 \\
\hline Ort. $E \pm S H$ & $0,621 \pm 0,089$ & $0,595 \pm 0,120$ & $0,630 \pm 0,110$ & $0,820 \pm 0,036$ & $0,667 \pm 0,089$ \\
\hline
\end{tabular}

\section{TARTISSMA ve SONUC}

$\mathrm{Bu}$ çalışmada incelenen hamsi balıklarının boy dağılım aralığının daha önce Karadeniz'de yapılan bazı çalışmalardan (Ünsal, 1989; Gözler ve Çiloğlu, 1998; Kayalı, 1998; Samsun vd., 2004) daha geniş, Cadiz Körfezi (Bellido vd., 2000), Akdeniz'in güneybatısındaki Batı Cezayir Benisaf Körfezi (Bacha vd., 2010) ve Karadeniz'de daha önce yapılmış bazı çalışmalardan (Karaçam ve Düzgüneş, 1990; Şahin vd., 2008) ise daha dar olduğu görülmüştür. Bu çalışmada en büyük balık boyu $13,8 \mathrm{~cm}$ olarak belirlenmişken, E. encrasicolus için şimdiye kadar yapılan çalışmalar içerisinde en büyük boy Karadeniz'den 16,9 cm (Karaçam ve Düzgüneş, 1990) olarak rapor edilmiştir. Maksimum boy Cadiz Körfezi'nde 18,5 cm (Bellido vd., 2000), Adriatik Denizi'nde 18,7 cm (Sinovcic, 2000), İzmir Körfezi'nde $14 \mathrm{~cm}$ (Uçkun vd., 2005) olarak rapor edilmiştir. Yine Karadeniz'de av sezonlarına göre hamsi yaş kompozisyonunun ve yaşlardaki ortalama boy değerlerinin değişiklik gösterdiği daha önce yapılan çalışmalarda detaylı olarak ortaya konulmuştur (Düzgüneş ve Karaçam, 1989; Erkoyuncu ve Özdamar, 1989; Ünsal, 1989; Karaçam ve Düzgüneş, 1990; Özdamar vd., 1994; Mutlu, 1994; Özdamar vd., 1995; Gözler ve Çiloğlu, 1998; Kayalı, 1998; Mutlu, 2000; Samsun vd., 2004; Samsun vd., 2006; Bilgin vd., 2006; Şahin vd., 2008; Sağlam ve Sağlam, 2013). Bu farklılıklar başta av baskıs1 olmak üzere, büyüme özelliklerinin zamana ve bölgelere göre farkl1lık göstermesinden, balık stoklarında dolaylı olarak değişime neden olan abiyotik çevresel faktörlerin (suyun yoğunluğu ve basıncı, tuzluluk, sıcaklık, besin tuzları, oksijen, 1şık, akıntı, rüzgâr ve yağış) yıllar arasında farklılıklar göstermesinden, yıllar arasındaki farklı prey-predatör ilişkisinden, besin madde miktarı ve besin kalitesindeki değişimlerin büyüme ve yeni birey katılımı üzerine olan etkisi gibi birçok faktörden dolayı kaynaklanmış olabileceği yine yukarıda bahsedilen çalışmalarda vurgulanmıştır.

Balıklarda büyüme matematiksel olarak genellikle von Bertalanffy büyüme modeline uygunluk gösterir. Ancak balıklarda büyümenin matematiksel olarak ifadesi; balık türüne, aynı tür içerisinde 
coğrafik bölgeye, cinsiyete, balık şekline, gonad olgunluk safhalarına, üreme zamanına, biyotik ve abiyotik çevresel faktörlere göre değişebilmektedir. Örneğin Zargana balığı (B. euxini) (Bilgin vd., 2014), İskorpit balığı (S. porcus) (Demirhan ve Can, 2009), Pervane balığı (M. lanceolatus) (Liu vd., 2009) ve Vatoz balığ̣ (B. minispinosa) (Ainsley vd., 2011) gibi balık türleri için büyüme farklı büyüme modellerine göre değerlendirilmiştir. Söz konusu balıklardaki farklı matematiksel büyüme modelleriyle değerlendirmeler, balığın vücut şekline, büyüme özelliklerine, büyüme parametrelerinin biyolojik olarak yorumlanmasına ve karşılaştırılmasındaki zorluklardan dolayı yapılmıştır (Fitzhugh, 1976). Farklı büyüme modellerinin en uygun olanını seçmek için $A I C$ nin ölçüt olarak kullanılması önerilmekle ve bu değer hangi modelde en küçükse o model matematiksel olarak en uygun model olarak değerlendirilmektedir (Akaike, 1974; Burnham ve Anderson, 2002; Henderson ve Seaby, 2006). Bunun yanında balığın büyüme özelliğinin büyüme modeline uygunluğu da model seçiminde diğer bir önemli ölçüt olarak dikkate alınmaktadır (Haddon, 2011). Çünkü uygun büyüme modelinin seçimi sadece matematiksel ya da istatistiksel uyumun kalitesine bağlı olamaz, aynı zamanda incelenen balığın biyolojisine dayanmalı ve büyümenin teorik bakış açısını yansıtmalıdır (Haddon, 2011). Büyüme eğrisinin bükülme noktasına karşılık gelen zaman ya da yaş parametresi (I), büyüme eğrisindeki üreme olgunluğuna karşıllk gelen yaş ya da maksimum büyümenin teorik zamanı olarak tanımlanır. Bu parametre genellikle hayvanlarda üreme olgunluğunun başlangıcı ile çakışır (Fitzhugh, 1976; Karkach, 2006). Bu çalışmada kullanılan büyüme modellerinden Gompertz (dişi $I=-0,51$, erkek $I=-0,89$ ) ve Lojistik (dişi $I=-0,38$, erkek $I=-0,68$ ) modellerinin parametrelerinden biri olan $I$ değeri her iki cinsiyet için de hem matematiksel hem de biyolojik olarak uygun bulunmamıştır. Diğer taraftan yukarıdaki açıklamalar akılda tutulduğunda, hem hesaplanan AIC sonuçları açısından [Weibull $(A I C=$ $2593,5)$ ve Morgan Mercer Flodin $(A I C=2593,8)]$ hem de hesaplanan $L_{\infty}$ ve $K$ parametreleri açısından [Weibull $\left(L_{\infty}=19,6 \mathrm{~cm}\right.$ ve $\left.K=0,031 \mathrm{yll}^{-1}\right)$ ve Morgan Mercer Flodin $\left(L_{\infty}=17,0 \mathrm{~cm}\right.$ ve $K=0,108{\mathrm{y} 11^{-}}^{-}$ $\left.{ }^{1}\right)$ ] erkek bireylerin büyümesini tanımlamak için Weibull ve Morgan Mercer Flodin büyüme modellerinin 6 büyüme modeli arasından en uygun model olduğu sonucuna ulaşılmıştır. Bunlara ilaveten, erkelerin büyümesinin hesap edildiği diğer 4 modelin $A I C$ kriterleri birbirine yakın olmasına rağmen söz konusu 4 modelde hesaplanan $L_{\infty}$ değerlerinin $\left(L_{\infty}<10,8 \mathrm{~cm}\right)$ biyolojik olarak erkek bireylerin büyümesini temsil etmediği düşünülmektedir. Şöyle ki, günümüze kadar yapılan otolit temelli büyüme çalışmaları incelendiğinde erkek bireylerin $L_{\infty}$ değerleri 13,82 cm (Ünsal, 1989) ile 18,40 cm (Samsun vd., 2006) arasında rapor edilmiştir (Tablo 8). Erkek bireylerin tersine, dişi bireyler için oluşturulan yaş-boy veri seti Weibull ve Morgan Mercer Flodin büyüme modelleri ile analiz edildiğinde matematiksel olarak sonuç hesaplanamamıştır. Dişi bireylerin büyümesini tanımlamak için kullanılan diğer 4 modelde ise $A I C$ değerleri von Bertalanffy $=$ Üssel $<$ Lojistik $<$ Gompertz şeklinde hesaplanmış olup, AIC ölçütü açısından von Bertalanffy $(A I C=5725,42)$ ve Üssel $(A I C=5725,42)$ büyüme modellerinin dişi bireylerin büyümesini tanımlamada en uygun modeller olduğu görülmüştür. Ancak dişi bireyler için hesaplanan büyüme parametreleri önceki çalışmalarla kıyaslandığında $K$ değerleri daha yüksek $L_{\infty}$ değerleri ise daha düşük bulunmuştur. Günümüze kadar Karadeniz ve diğer bölgelerde yapılan çalışmaların sonucunda dişi bireylerin erkeklerden daha büyük boya ulaştıkları ve erkeklere göre daha hızlı büyüdükleri bildirilmiştir (Ünsal, 1989; Gözler ve Çiloğlu, 1998; Samsun vd., 2004; Bilgin vd., 2013; Bellido vd., 2000; Bacha vd., 2010). Bu durum bu çalışma sonuçlarıyla da örtüşmektedir.

Hamsi balığı hızlı büyüyen ve yaklaşık 1 yaşında cinsi olgunluğa erişen (\%50 cinsi olgunluk boyu Kayalı (1998) tarafından dişiler için 9,3 cm, erkekler için ise 8,9 cm olarak rapor edilmiştir) bir balık olmasının yanında büyüme hızı ve büyüme performansı yıllara ve bölgelere göre farklılıklar gösterebilmektedir. Bu farklılıklar, üzerinde çalışılan bireylerin boy ve yaş kompozisyonunun farklılık arz etmesinden, büyüme üzerine etkisi olan yarış, prey-predatör ilişkisi gibi biyotik ve başta sıcaklık dalgalanmaları olmak üzere hamsinin besinini oluşturan bitkisel ve hayvansal kökenli plankton bolluğundaki dalgalanmalar, fito-plankton biomas indeksi olarak kabul edilen klorofil - $a$ konsantrasyonundaki dalgalanmalar gibi abiyotik çevresel faktörlerin yıllar ve bölgelere göre farklılık göstermesinden kaynaklanabilmektedir (Avşar, 2005; Bat vd., 2007; Ağırbaş vd., 2010; Bilgin vd., 2016). Ayrıca Karadeniz'de yıllar arasında av baskısı, doğal ölüm ve avcılık ölüm oranındaki farklılıklarda (Tablo 9) hamsi balığının büyümesine etki eden diğer bir önemli faktör olarak düşünülmelidir. $\mathrm{Bu}$ farkl1lıklar hamsinin büyümesinde mevsimsel olarak ta etki etmekte ve Karadeniz'de hamsinin mevsimsel büyüme özelliği göstermesine neden olmaktadır (Bilgin vd., 2016). 
Tablo 8. Farklı bölgelerden ve farklı av mevsimlerine göre hamsi için rapor edile büyüme parametreleri. $L_{\infty}=$ asymptotik boy $(\mathrm{cm}), K=$ büyüme katsayısı $\left(\right.$ yıl $\left.{ }^{-1}\right), \Phi^{\prime}=$ büyüme performans indeksi. $L_{\max }=$ maksimum toplam boy $(\mathrm{cm}), L_{\text {ort }}=$ ortalama boy $(\mathrm{cm})$

\begin{tabular}{|c|c|c|c|c|c|c|c|c|c|c|c|c|c|c|c|c|}
\hline \multirow{2}{*}{$\begin{array}{l}\text { Av } \\
\text { Sezonu }\end{array}$} & \multicolumn{5}{|l|}{ Erkek } & \multicolumn{5}{|l|}{ Dişi } & \multicolumn{5}{|c|}{ Tüm (dişi+erkek) } & \multirow{2}{*}{ Kaynak } \\
\hline & $\boldsymbol{L}_{\infty}$ & $K$ & $\Phi^{\prime}$ & $L_{\max }$ & $L_{\text {ort. }}$ & $\boldsymbol{L}_{\infty}$ & $K$ & $\Phi^{\prime}$ & $L_{\max }$ & $L_{\text {ort }}$ & $\boldsymbol{L}_{\infty}$ & $K$ & $\Phi^{\prime}$ & $L_{\max }$ & $L_{\text {ort }}$ & \\
\hline $1985-1986$ & & & & & & & & & & & 16,77 & 0,324 & 1,960 & 16,1 & 12,4 & 1 \\
\hline $1986-1987$ & & & & & & & & & & & 16,85 & 0,324 & 1,964 & 16,9 & 10,8 & 2 \\
\hline $1987-1988$ & & & & & & & & & & & 14,14 & 0,920 & 2,265 & & & 3 \\
\hline $1987-1988$ & & & & & & & & & & & 17,99 & 0,294 & & 15,3 & 9,8 & 4 \\
\hline 1988-1989 & & & & & & & & & & & 15,65 & 0,282 & & 13,5 & 10,6 & 4 \\
\hline 1988-1989 & 13,82 & 0,528 & 2,004 & 13,0 & & 14,03 & 0,583 & 2,060 & 13,0 & & 15,73 & 0,317 & 1,895 & 13,0 & & 5 \\
\hline 1994-1995 & & & & & & & & & & & 16,83 & 0,310 & 1,944 & 15,3 & 9,0 & 6 \\
\hline $2000-2001$ & 15,86 & 0,273 & 1,837 & 13,8 & 10,9 & 19,27 & 0,167 & 1,793 & 14,1 & 11,2 & 16,84 & 0,233 & 1,820 & & 10,7 & 7 \\
\hline 2001-2002 & 17,37 & 0,237 & 1,854 & 13,6 & 10,9 & 19,94 & 0,202 & 1,905 & 14,6 & 11,8 & 18,46 & 0,217 & 1,869 & & 11,3 & 7 \\
\hline $2002-2003$ & 18,40 & 0,177 & 1,778 & 13,3 & 10,0 & 18,78 & 0,154 & 1,735 & 14,9 & 10,6 & 18,73 & 0,156 & 1,738 & & 10,2 & 7 \\
\hline 1974-1990 & & & & & & & & & & & 19,40 & 0,570 & 2,331 & & & 8 \\
\hline 1989-1993 & & & & & & & & & & & 18,95 & 0,900 & 2,509 & 18,5 & & 9 \\
\hline $1989-1993$ & & & & & & & & & & & 18,69 & 0,900 & 2,000 & 18,5 & & 9 \\
\hline 2007 & 15,36 & 0,780 & 2,265 & & & 15,76 & 0,790 & 2,293 & & & 15,61 & 0,750 & 2,262 & 17,0 & & 10 \\
\hline $2010-2011$ & 13,01 & 0,993 & 2,226 & 13,8 & 11,2 & 13,69 & 1,249 & 2,369 & 14,4 & 11,8 & & & & & & 11 \\
\hline $2010-2011$ & 14,00 & 0,800 & 2,195 & 13,4 & 11,3 & 13,93 & 0,994 & 2,285 & 14,6 & 11,8 & & & & & & 11 \\
\hline
\end{tabular}




\section{Ölüm oranları ve işletme oranı}

Av sezonlarına göre hamsi üzerine yapılmış önceki çalışmalardan hesaplanan ölüm oranı parametreleri (toplam ölüm oran1, doğal ölüm oranı ve balıkç1lı ölüm oranı) sonuçlarına göre, Karadeniz'de avlanan hamsinin balıkçılık ölüm oranıyla toplam ölüm oranının av sezonları boyunca benzer şekilde dalgalanmalar gösterdiği, işletme oranının ise optimum seviyenin $(E=0,5)$ üzerinde olduğu görülmektedir (Tablo 9). Bu çalışmada, av eğrisi yöntemine göre hesaplanan dişilerin toplam ölüm katsayısı $\left(Z=3,5 \mathrm{y}_{1} 1^{-1}\right)$ erkeklerden $\left(Z=3,3\right.$ yıl $\left.^{-1}\right)$ biraz daha büyük hesaplanmıştır $\left(Z_{\text {dişi }}>Z_{\text {erkek }}\right)$. Yine 6 büyüme modeli için hesaplanan büyüme parametreleri 4 doğal ölüm oranı formüllerinde yerine konularak hesaplanan ölüm oranlarına göre dişi bireylerin doğal ölüm oranının erkeklerden daha büyük olduğu hesaplanmıştır $\left(M_{\text {dişi }}>M_{\text {erkek }}\right)$. Erkek bireyler için tüm model sonuçlarına göre hesaplanan işletme oranı 0,5 değerinden büyük hesaplanmışken, dişi bireyler için sadece Djabali vd. (1993) yöntemine göre hesaplanan ölüm oranı (ortalama $M=1,014 \pm 0,016 \mathrm{y}_{1} 1^{-1}$ ) kullanılarak hesaplanan ortalama işletme oranı (ortalama $E=0,706 \pm 0,005$ ) 0,5 değerinden yüksek hesaplanmıştır. Farklı büyüme modeli parametreleri kullanılarak hesaplanan doğal ölüm oranları ve $M$ verileri kullanılarak hesaplanan işletme oranı değerleri 2014-2015 av sezonunda hamsi stokunun optimum değerden $(E=0,5)$ daha yüksek bir derecede işletildiğini yani av baskısı altında olduğunu göstermiştir.

Tablo 9. Hamsinin Karadeniz'de av sezonlarına göre rapor edilen toplam ölüm oranı $(Z)$, doğal ölüm oranı $(M)$, balıkçılık ölüm oranı $(F)$ ve işletme oranı $(E)$ değerleri

\begin{tabular}{|c|c|c|c|c|c|}
\hline \multirow[b]{2}{*}{ Av sezonları } & \multicolumn{4}{|c|}{ Parametre } & \multirow[b]{2}{*}{ Kaynak } \\
\hline & $Z\left(\mathrm{yll}^{-1}\right)$ & $M\left(\mathrm{yll}^{-1}\right)$ & $F\left(\mathrm{yll}^{-1}\right)$ & $E\left(\mathrm{yll}^{-1}\right)$ & \\
\hline $1985-1986$ & 1,56 & 0,46 & 1,10 & 0,71 & Erkoyuncu ve Özdamar, 1989 \\
\hline $1986-1987$ & 1,05 & 0,53 & 0,52 & 0,50 & Karaçam ve Düzgüneş, 1990 \\
\hline $1987-1988$ & 1,40 & 0,57 & 0,83 & 0,59 & Düzgüneş ve Karaçam, 1989 \\
\hline $1987-1988$ & 1,06 & 0,46 & 0,60 & 0,57 & Özdamar vd., 1994 \\
\hline $1988-1989$ & 1,23 & 0,45 & 0,78 & 0,63 & Özdamar vd., 1994 \\
\hline $1988-1989$ & 0,87 & 0,50 & 0,37 & 0,43 & Ünsal, 1989 \\
\hline $1993-1994$ & 1,61 & 0,53 & 1,08 & 0,67 & Mutlu, 1994 \\
\hline $1994-1995$ & 1,25 & 0,47 & 0,78 & 0,62 & Özdamar vd., 1995 \\
\hline $1996-1997$ & 2,08 & 0,68 & 1,40 & 0,67 & Kayalı, 1998 \\
\hline $1997-1998$ & 2,07 & 0,67 & 1,40 & 0,68 & Mutlu, 2000 \\
\hline $1997-1998$ & 1,37 & 0,49 & 0,88 & 0,64 & Gözler ve Çiloğlu, 1998 \\
\hline $1998-1999$ & 1,44 & 0,49 & 0,95 & 0,66 & Samsun vd., 2004 \\
\hline $1999-2000$ & 1,60 & 0,46 & 1,14 & 0,71 & Samsun vd., 2004 \\
\hline $2000-2001$ & 3,59 & 0,36 & 3,23 & 0,90 & Samsun vd., 2006 \\
\hline $2001-2002$ & 3,37 & 0,35 & 3,02 & 0,90 & Samsun vd., 2006 \\
\hline $2002-2003$ & 1,90 & 0,29 & 1,61 & 0,85 & Samsun vd., 2006 \\
\hline $2004-2005$ & 1,85 & 0,34 & 1,51 & 0,82 & Bilgin vd., 2006 \\
\hline $2004-2005$ & 0,99 & 0,45 & 0,54 & 0,55 & Şahin vd., 2008 \\
\hline $2005-2006$ & 1,56 & 0,54 & 1,02 & 0,65 & Şahin vd., 2008 \\
\hline $2010-2011$ & 2,84 & 0,66 & 2,18 & 0,77 & Sağlam ve Sağlam, 2013 \\
\hline
\end{tabular}

Sonuç olarak, otolit temelli farklı büyüme modelleriyle belirlenen büyüme parametreleri kullanılarak, hesaplanan işletme oranı sonuçları; hamsi avcılığında aşırı av baskısının olduğunu bir kez daha ortaya koymuştur. Sürüdürebilir balıkçılık için av baskısının azaltılmasının (örneğin av çabasını kısıtlayıcı tedbirlerin artırılması) yanında, ileriki çalışmalarda hamsinin farklı av sezonlarında büyümesinin belirlenmesinde cinsiyetlere göre farklı büyüme modellerinin kullanılması örneğin bu çalışma sonuçlarına göre erkekler için Weibull ve Morgan Mercer Flodin, dişiler için ise von Bertalanffy ve Üssel büyüme modellerinin kullanılması önerilmiştir.

Teşekkür: Bu çalışma, yüksek lisans tezinden özetlenmiştir. Çalışma Recep Tayyip Erdoğan Üniversitesi, Su Ürünleri Fakültesi, Su Ürünleri Avlama ve İşleme Teknolojisi Bölümü tarafından 
desteklenmiştir.

\section{KAYNAKLAR}

Ağırbaş, E., Seyhan, K., Kasapoğlu, N., Feyzioğlu, M., Üstündağ, E., \& Eruz, C. (2010). Recent changes of the Turkish anchovy fishery in the black sea with special reference to climate change. Journal of Environmental Protection and Ecology, 11(4), 1495 - 1503.

Ainsley, S.M., Ebert, D.A., \& Cailliet, G.M. (2011). Age, growth, and maturity of the whitebrow skate, Bathyraja minispinosa, from the eastern Bering Sea. ICES Journal of Marine Science, 68, 1426-1434.

Akaike, H. (1974). A new look at the statistical model identification. Automatic Control, IEEE Transactions, 19, 716-723.

Alagaraja, K. (1984) Simple methods for estimation of parameters for assessing exploited fish stoks. Indian Journal of Fisheries, 31, 177-208

Avşar, D. (2005). Balıkçıllk biyolojisi ve populasyon dinamiği. Nobel Kitabevi, Adana.

Bacha, M., Moali, A., Benmansour, N-E., Brylinski, J-M., Mahé, K., \& Amara, R. (2010) Relationship between age, growth, diet and environmental parameters for anchovy (Engraulis encrasicolus L.) in the Bay of Bénisaf (SW Mediterranean, west Algerian coast). Cybium, 34(1), 47-57.

Bat, L., Şahin, F., Satılmış, H.H., Üstün, F., Birinci Özdemir, Z., Kıdeys, A.E., \& Shulman, G.E. (2007). The changed ecosystem of the Black Sea and its impact on anchovy fisheries. Journal of FisheriesSciences.com, 1, 191-227.

Bellido, J.M., Pierce, G.J., Romero, J.L., \& Millán, M. (2000). Use of frequency analysis methods to estimate growth of anchovy (Engraulis encrasicolus L. 1758) in the Gulf of Cádiz (SW Spain). Fisheries Research, 48, 107-115.

Bilgin, S. (2006). Evaluated of anchovy, Engraulis encrasicolus (L., 1758), fishing (1985-2005 fishing seasons) Turkish coast (Black Sea) in respect to fisheries biology. Erciyes University, Journal of Science and Technology, 22(1-2), 213-222.

Bilgin, S., Samsun, N., Samsun, O., \& Kalayc1, F. (2006). Estimation of population parameters of anchovy, Engraulis encrasicolus L. 1758, at 2004-2005 fishing season in the Middle Black Sea, using length frequency analysis methods. Ege Journal of Fisheries and Aquatic Sciences, 23(1/3), 359-364.

Bilgin, S., Taşçı, B., \& Bal, H. (2013). Sexual seasonal growth of the European anchovy (Engraulis encrasicolus) caught by mid-water trawl and purse seine in the southern Black Sea. Journal of the Marine Biological Association of the United Kingdom, 93(2), 333-339.

Bilgin, S., Taşçı, B., \& Bal, H. (2014). Population dynamics of the garfish, Belone euxini (Belonidae: Belone) from the south-east Black Sea. Journal of the Marine Biological Association of the United Kingdom, 94(8), 1687-1700.

Bilgin, S., Sümer, Ç., Bektaş, S., Satılmış, H.H., \& Bircan, R. (2016). Evaluation of anchovy (Engraulis encrasicolus) population dynamics studies (1985-2015) in terms of fisheries management in the Black Sea. Ege Journal of Fisheries and Aquatic Sciences, 33(2), 169-182.

Burnham, K.P., \& Anderson, D.R. (2002). Model selection and inference. A practical information-theoretic approach. Springer-Verlag, New York.

Cochrane, K.L. (2002). A fishery manager's guidebook. Management measures and their application. FAO press, Rome.

Demirhan, S.A., \& Can, M.F. (2009). Age, growth and food composition of Scorpaena porcus (Linnaeus, 1758) in the southeastern Black Sea. Journal of Applied Ichthyology, 25, 215-218.

Djabali, F., Mehailia, A., Koudil, M., \& Brahmi, B. (1993). Empirical equations for the estimation of natural mortality in Mediterranean teleosts. Naga, the Iclarm Quarterly, 16, 35-37.

Düzgüneş, E., \& Karaçam, H. (1989). Studies on some population parameters and growth of the European anchovy (Engraulis encrasicolus, Linnaeus, 1758) in the Black Sea. Doga Turkish Journal of Zoology, $13,77-83$.

Erkoyuncu, İ. (1995). Balıkçıllk Biyolojisi ve Populasyon Dinamiği, Ondokuz Mayıs Üniversitesi Yayınları, Samsun.

Erkoyuncu, I., \& Ozdamar, E. (1989). Estimation of the age, size and sex composition and growth parameters of anchovy, Engraulis encrasicolus (L.) in the Black Sea. Fisheries Research, 7, 241-247.

Everhart, W.H., Eipper, A.W., \& Youngs, W.D. (1975). Principles of fishery sciences. Cornell University Press, New York.

Fitzhugh, H.A. (1976). Analysis of growth curves and strategies for altering their shape. Journal of Animal Science, 42(4), 1036-1051.

Gompertz, B. (1825). On the nature of the function expressive of the law of human mortality and on a new mode of determining the value of life contingencies. Philosophical Transactions of the Royal Society of London, 
Gözler, A.M., \& Çiloğlu, E. (1998). A study on some population parameters of anchovy (Engraulis encrasicolus L., 1758) caught 1997- 1998 fishing season off Rize-Hopa. Eastern Anatolia Region III. Symposium on Fisheries 1998 (pp. 373-382). Erzurum, Turkey. Proceedings Book.

Haddon, M. (2011). Modelling and quantitative methods in fisheries. CRC Pres, Boca Raton, London, New York.

Hammer, Ø., Harper, D.A.T., \& Ryan, P.D. (2001). PAST: Paleontological Statistics Software Package for Education and Data Analysis. Palaeontologia Electronica 4(1), 1-9.

Henderson, P.A,. \& Seaby, R.M. (2006). Growth II. Pisces Conservation Ltd. Pres, Lymington, Hampshire.

Karacam, H., \& Düzgünes, E. (1990). Age, growth and meat yield of the European anchovy (Engraulis encrasicolus, L. 1758) in the Black Sea. Fisheries Research, 9, 181-186.

Karkach, A.S. (2006) Trajectories and models of individual growth. Demographic research, 15, 347-400.

Kayal1, E. (1998). A study on the biological characteristics of anchovy (Engraulis encrasicolus, L., 1758) and horse mackerel (Trachurus mediterranues) in the Eastern Black Sea ecosystem. M.Sc Thesis, Black Sea Technical University, Institute of Science and Technology, Department of Fisheries Technology Engineering, 238 p, Trabzon, Turkey.

Lisovenko, L.A., \& Andrianov, D.P. (1996). Reproductive biology of anchovy (Engraulis encrasicolus ponticus Alexandrov 1927) in the Black Sea. Scientia Marina, 60 (2), 209-218.

Liu, K.M., Lee, M.L., Joung, S.J., \& Chang, Y.C. (2009). Age and growth estimates of sharptail mola, Masturus lanceolatus, in waters of eastern Taiwan. Fisheries Research, 95, 154-160.

Mazlum, R.E., Solak, E., \& Bilgin, S. (2017). Size and seasonal diet variation of European anchovy, Engraulis encrasicolus (Linnaeus, 1758) in the southeast Black Sea. Cahiers de Biologie Marine, 58(3), 251-260.

Morgan, P.H., Mercer, L.P., \& Flodin, N.W. (1975). General model for nutritional response of higher organisms. Proceedings of the National Academy of Sciences of the United States of America, 72, 4327-4331.

Mutlu, C. (1994). A study on the some population characteristics of anchovy (Engraulis encrasicolus, L., 1758) in the Eastern Black Sea. M.Sc Thesis, Black Sea Technical University, Institute of Science and Technology, Department of Fisheries Technology Engineering, 44 p, Trabzon, Turkey.

Mutlu, C. (2000). Population characteristics and implementation of analytical methods for the prediction of the stock quantity of anchovy (Engraulis encrasicolus Linnaeus, 1758) in the Eastern Black Sea. PhD Thesis, Black Sea Technical University, Institute of Science and Technology, Department of Fisheries Technology Engineering, 112 p, Trabzon, Turkey.

Özdamar, E., Kihara, K., Sakuramoto, K., \& Erkoyuncu, I. (1994). Variation in the population structure of European anchovy, Engraulis encrasicolus, L. in the Black Sea. Journal of Tokyo University of Fisheries, $81,2,123-134$.

Özdamar, E., Samsun, O., \& Erkoyuncu, I. (1995). The estimation of population parameters for anchovy (Engraulis encrasicolus, L.) during 1994-1995 fishing season in the Turkish Black Sea region. Ege University Faculty of Fisheries, Journal of Fisheries and Aquatic Sciences, 12(1-2), 135-144.

Pauly D. (1980). On the interrelationships between natural mortality, growth parameters, and mean environmental temperature in 175 stocks. Journal du Conseil International pour i'Exploration de la Mer, 39, 175-192.

Pauly D. (1984). Fish population dynamics in tropical waters: a manual for use with programmable calculators. Makati, Metro, Manila, Philippines. ICLARM Contribution, no. 143, $325 \mathrm{pp}$.

Pauly, D., \& Munro, J.L. (1984). Once more on the comparison of growth in fish and invertebrates. ICLARM Fishbyte, 2, 21.

Prodanov, K., Mikhailov, K., Daskalov, G., Maxim, C., Chashchin, A., Arkhipov, A., Shlyakhov, V., \& Ozdamar, E. (1997). Environmental management of fish resources in the Black Sea and their rational exploitation. Studies and Reviews. General Fisheries Council for the Mediterranean, FAO Press, Rome.

Quinn, T.J., \& Deriso, R.B. (1999). New quantitative fish dynamics. Oxford University Press, Oxford.

Richards, F.J. (1959). A flexible growth functions for empirical use. Journal of Experimental Botany, 10, 290 301.

Ricker, W.E. (1975). Computation and interpretation of biological statistics of fish populations. Department of the Environment Fisheries and Marine Service Press, Ottawa.

Sağlam, N.E., \& Sağlam, C. (2013). Age, growth and mortality of anchovy Engraulis encrasicolus in the southeastern region of the Black Sea during the 2010-2011 fishing season. Journal of the Marine Biological Association of the United Kingdom, 93, 2247-2255.

Samsun, O., Samsun, N., \& Karamollaoğlu, A.C. (2004). Age, growth and mortality rates of the European anchovy (Engraulis encrasicolus L. 1758) in the Turkish Black Sea Coast. Turkish Journal of Veterinary and Animal Sciences, 28(5), 901-910.

Samsun, O., Samsun, N., Kalayc1, F., \& Bilgin, S. (2006). A study on recent variations in the population structure of European Anchovy (Engraulis encrasicolus L., 1758) in the southern Black Sea. Ege University Journal of Fisheries and Aquatic Sciences, 3-4, 306. 
Sinovcic, G. (2000). Anchovy, Engraulis encrasicolus (Linnaeus, 1758): biology, population dynamics and fisheries case study. Acta Adriatia, 41, 1, 3-53.

Slastenenko, E. (1955-1956). Karadeniz havzası balıkları. Et ve Balık Kurumu Umum Müdürlüğü Yayınları, İstanbul.

Srinath, M. (1998). Empirical relationships to estimate the instantaneous rate of natural mortality. Indian Journal of Fisheries, 45, 7-11.

Şahin, C., Akın, Ş., Hacımurtazaoğlu, N., Mutlu, C., \& Verep, B. (2008). The stock parameter of anchovy (Engraulis encrasicolus) population on the coasts of the eastern Black Sea: reason and implications in declining of anchovy population during the 2004 - 2005 and 2005 - 2006 fishing seasons. Fresenius Environmental Bulletin, 17(12b), 2159-2169.

Uçkun, D., Akalin, S., \& Toğulga, M. (2005). Investigations of the age and growth of anchovy (Engraulis encrasicolus L., 1758) in Izmir Bay. E.U. Journal of Fisheries \& Aquatic Sciences, 22, (3-4), 281-285.

Ünsal, N. (1989). A study on age-length-weight relationship and determination of the smallest catching size of anchovy, Engraulis encrasicolus (L.) in the Black Sea. Istanbul University Journal of Aquatic Products, 3(1-2), 17-28.

von Bertalanffy, L. (1938) A quantitative theory of organic growth (Inquiries on growth laws. II). Human Biology, 10, 181-213.

von Bertalanffy, L. (1951). Metabolic types and growth types. The American Naturalist, LXXXV 821, 111-117.

Weibull, W. (1951). A statistical distribution functions of wide applicability. Journal of Applied Mechanics, Transactions of the ASME, 18, 293-297. 